\title{
Consulting the patients: Avastin in the treatment of Wet AMD (Part II)
}

\author{
Ryian Mohamed (10 ${ }^{1} \cdot$ David C. Saunders ${ }^{1} \cdot$ John P. Mathews ${ }^{1}$
}

Received: 11 January 2019 / Accepted: 18 January 2019 / Published online: 13 February 2019

(c) The Royal College of Ophthalmologists 2019

As medicine has moved away from a paternalistic approach, 'patient choice' is increasingly viewed as a key aspect of healthcare delivery. Of note, is the central importance of patient preference in the High court ruling [1] regarding Avastin use in wet age-related macular degeneration (AMD). CCG's now have a legal precedent to recommend health care professionals offer Avastin in addition to Lucentis or Eylea when providing intra-vitreal treatment (IVT), with the onus on patients to make the final treatment choice.

Those in favour of offering patients this choice, such as David Hambleton, chief executive officer of NHS South Tyneside CCG, one of 12 CCG's involved in the legal dispute/case, argue: 'We believe that they [patients] will support very strongly having a cost-effective, safe treatment and saving the NHS generally a lot of money. It is a victory for common sense over commercial interests' [2]. Those in opposition, the drug companies Bayer and Novartis counter argue that 'This sets a dangerous precedent, which we should all be concerned about. Today, people living with wet AMD are now being asked to compromise on the assured quality and safety of their treatment, purely on the basis of cost. This is inappropriate and unnecessary' [3]. What is missing from this debate are the voices of the patients themselves. We conducted a survey questionnaire (see appendix 1) to determine directly from patients attending IVT clinic for wet AMD treatment $(n=38)$ with either Lucentis or Eylea, how they viewed the Avastin High

Supplementary information The online version of this article (https:// doi.org/10.1038/s41433-019-0366-6) contains supplementary material, which is available to authorized users.

Ryian Mohamed m0601207@gmail.com

1 Betsi Cadwaladr University Health Board, Abergele Hospital, Abergele, UK
Court Ruling, its consequence and likely impact for their eye health.

We found a variable response as to the underlying concerns governing patient choice when considering IVT treatment. No single domain assessed was unanimously of importance or unimportance to patients, rather participants agreed or disagreed across parameters randomly (See Fig. 1). This is interesting, as it highlights just how diverse the concerns of patients undergoing IVT treatment can be. Most patients, after all, are not medically trained to evaluate the treatment they receive and so it is reasonable that varying ideas, concerns and expectations should abound and co-exist. This suggests that planning IVT services in line with patient choice may be a more complicated matter than those debating over clinical policy assume.

What clearly emerged from our work was that the majority $(71 \%)$ of patients surveyed, if offered, would not be likely to choose Avastin, with only $18 \%$ of patients confident in choosing Avastin instead of Lucentis or Eylea. Most patients, $87 \%$, were clear that they would like to make the choice of which eye injection they received, and only $13 \%$ did not like having to make the choice. If these findings (See Fig. 2) are replicated across other centres within the United Kingdom, then it suggests the High Court Ruling impact on future planning and delivery of IVT services may be minimal as most patients will not choose Avastin.

Additionally, there have been recent calls for a patient information leaflet to aid the consultation process, with moves by the Royal College of Ophthalmologists, in a recent members briefing, towards creating a patient leaflet [4]. Our results would support such a move by the College as $84 \%$ of patients surveyed felt a patient information leaflet would be useful and only $13 \%$ felt that it would not be useful (See Fig. 2).

In our previously published, Consulting the consultants: Avastin in the treatment of wet AMD [5], we reported on the challenges facing medical professionals in offering wet 
The biggest issue in choosing Avastin (instead of Lucentis or Eylea) to treat my condition would be:

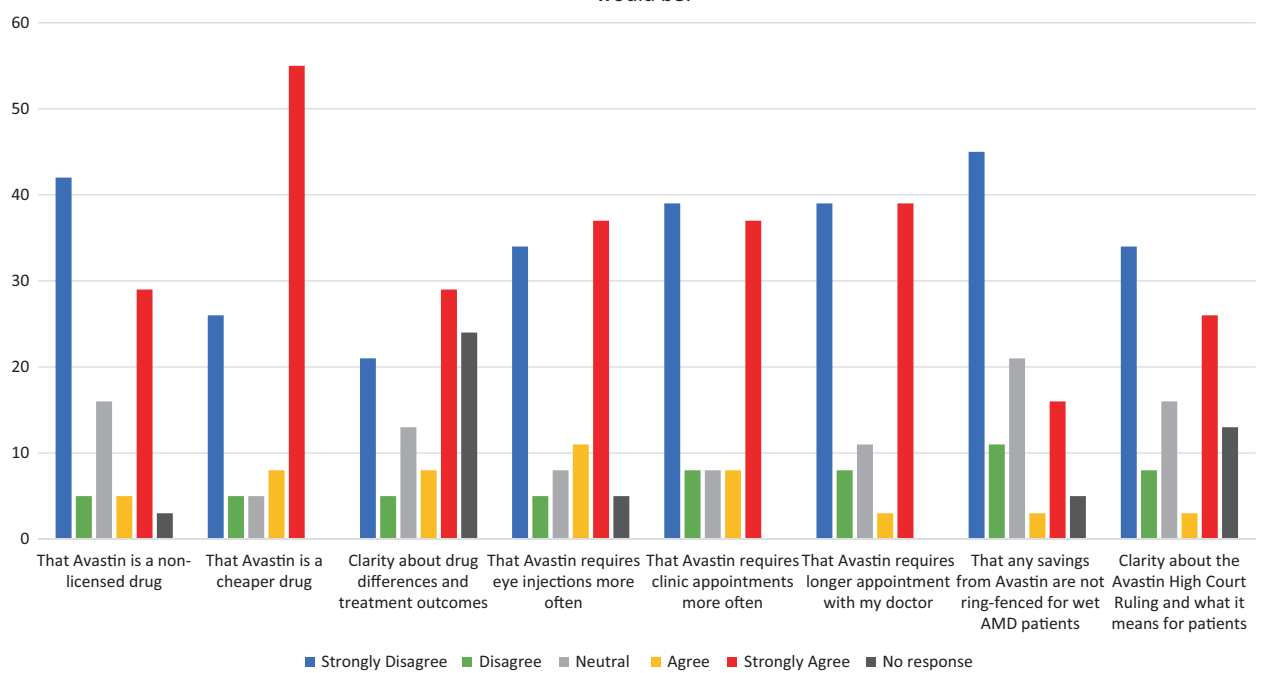

Fig. 1 Summary of patient survey questionnaire results: As a patient with Wet AMD, the biggest issue in choosing Avastin (instead of Lucentis or Eylea) to treat my condition would be:

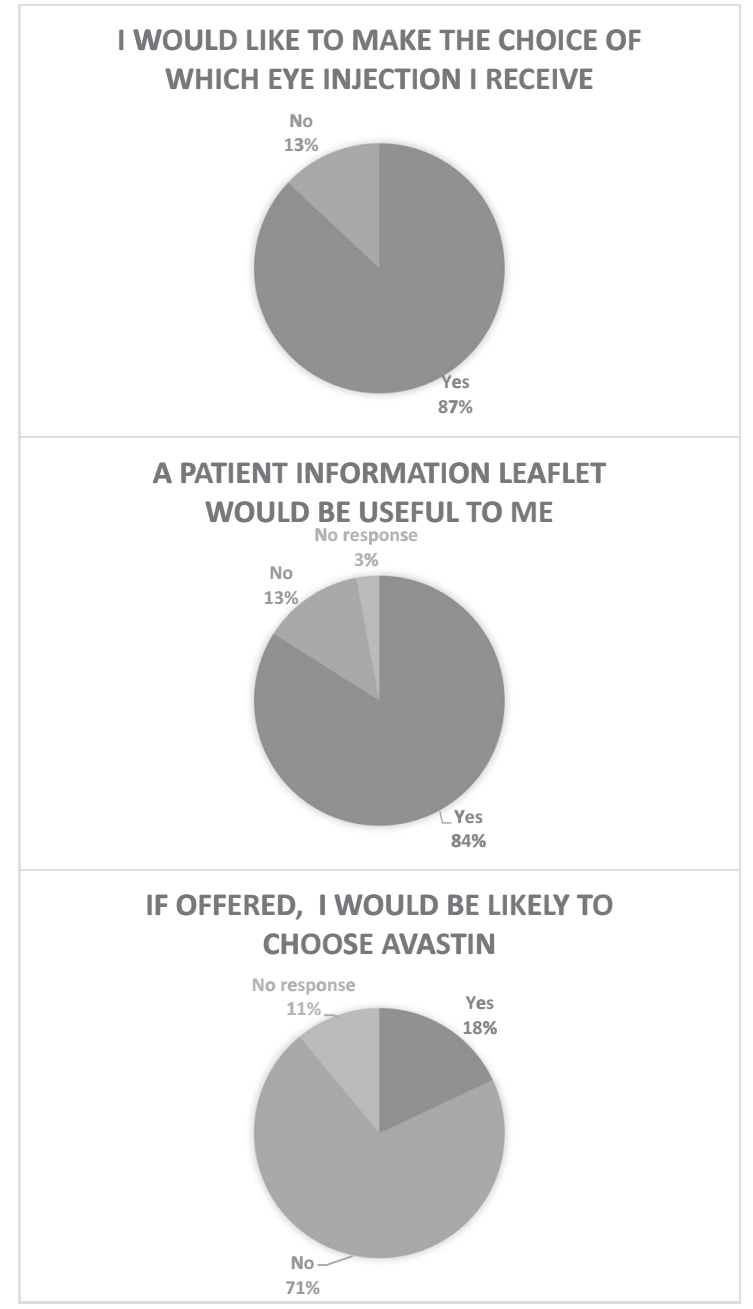

Fig. 2 Summary of patient survey questionnaire results: Regarding the choice between Avastin, Lucentis or Eylea?
AMD patients Avastin. In coming full circle, we have sought to do the same for patients. Determining ultimately whether it is a good or bad day to be a wet AMD patients will rest largely on how effectively Health care professionals seek to understand and assimilate patient views when planning and providing clinical care. Excellence for wet AMD patients will require strategic efforts in pathway mapping and patient focus groups to enhance understanding of highly variable patient needs and concerns. Large scale first-line use of Avastin in wet AMD may not be achievable within current service delivery models as patients are unlikely to choose Avastin.

\section{Disclaimer}

We confirm the manuscript has not been published elsewhere and is not under consideration by another journal. All authors have approved the manuscript and agree with submission.

Acknowledgements We would like to thank the nursing staff at the Abergele IVT Suit for coordinating the distribution and collection of patient questionnaires.

\section{Compliance with ethical standards}

Conflict of interest The authors declare that they have no conflict of interest.

Publisher's note: Springer Nature remains neutral with regard to jurisdictional claims in published maps and institutional affiliations. 


\section{References}

1. High Court APPROVED judgement, case no: CO/5288/2017. https://www.judiciary.uk/wp-content/uploads/2018/09/bayer-andnovartis-v-nhs-darlington-ccg-judgment. Accessed October 2018.

2. NHS bosses win landmark legal battle against drug firms. Macuar Society. Online article. https://www.macularsociety.org/news/nhsbosses-win-landmark-legal-battle-against-drug-firms.

Accessed December 2018.

3. Insight news. Online article. https://www.insightnews.com.au/ Article3/1966/Novartis-and-Bayer-to-fight-unlawful-UK-court-

judgment-allowing-new-AMD-treatment. Accessed December 2018.
4. Avastin Update - briefing from The Royal College of Ophthalmologists. Online article. https://www.rcophth.ac.uk/wp-content/ uploads/2018/10/Avastin-briefing_1.pdf?_cldee $=$ cnlpYW4ubW9o YW11ZEB6b2hvLmNvbQ\%3d\%3d\&recipientid = contact-0dd3e9b 3ae02e711944e00155d000b47-2238942225084b1d9aef496d5e92 ee79\&esid=efe755cc-1dce-e811-94ac-00155de1ae00\&urlid $=1$. Accessed December 2018.

5. Mohamed R, Saunders DC, Mathews JP. Consulting the consultants: Avastin in the treatment of wet AMD. Eye. 2018 https://doi.org/10.1038/s41433-018-0260-7. e-pub ahead of print. 5 November 2018 